\title{
TATA KELOLA TAMAN BACAAN MASYARAKAT "MELATI" DESA KOLAM SEBAGAI SARANA BELAJAR ANAK DI MASA COVID-19
}

\author{
Wildansyah Lubis, Waliyul Maulana Siregar, Jubaidah Hasibuan, Lala \\ Jelita Ananda
}

Surel: ljananda.84@gmail.com

\begin{abstract}
At the beginning of the establishment of the reading park it was intended as a means of reading for the community, but due to the Covid-19 pandemic, the reading garden no longer functions as it used to, there was a decrease in visits by people who initially visited the reading garden a lot. Based on observations, the decrease in the interest of reading garden visitors was caused by several things, namely 1) the design of the reading park location was not well organized;2) A collection of reading gardens that are less varied and not updated; 3) Social restrictions imposed during the Covid-19 pandemic; and 4) the lack of understanding of the management of the reading park (Community for the Children of the Pond Village and Karang Taruna) regarding the management of an attractive reading park and in accordance with health protocol standards during the Covid-19 pandemic. Therefore, based on this problem, a solution was agreed upon to provide strengthening of the governance of the community reading garden for the Children's Community in the Pool Village and the Karang Taruna in the Pool Village as the manager of the "Melati" Community Reading Park in the Pool Village and make the reading garden a means of learning for children during the Covid period. -19 .
\end{abstract}

Keywords: Community Reading Gardens, Children's Learning Facilities, Covid19

\section{ABSTRAK}

Pada awal pendirian taman baca tersebut ditujukan sebagai sarana membaca bagi masyarakat, namun disebabkan Pandemi Covid-19 membuat taman baca tersebut tidak lagi berfungsi sebagaimana awalnya, terjadi penurunan kunjungan oleh masyarakat yang pada awalnya banyak berkunjung ke taman baca tersebut. Berdasarkan hasil observasi penurunan minat pengunjung taman baca disebabkan beberapa hal, yaitu 1) Desain lokasi taman baca yang kurang ditata dengan baik; 2) Koleksi taman baca yang kurang variatif dan tidak diperbaharui; 3) Pembatasan sosial yang diberlakukan selama masa pandemi Covid-19; dan 4) kurangnya pemahaman pengelola taman bacaan (Komunitas Anak Desa Kolam dan Karang Taruna) tentang pengelolaan taman baca yang menarik dan sesuai dengan standar protokol kesehatan di masa pandemic Covid-19. Maka dari itu, berdasarkan permasalahan ini disepakati sebuah solusi untuk memberikan penguatan tata kelola taman baca masyarakat kepada Komunitas Anak Desa Kolam dan Karang Taruna Desa Kolam sebagai pengelola Taman Bacaan Masyarakat "Melati" Desa Kolam dan menjadikan taman baca tersebut sebagai sarana belajar anak di masa Covid-19.

Kata Kunci: Taman Baca Masyarakat, Sarana Belajar Anak, Covid-19 


\section{PENDAHULUAN}

Demi memenuhi kebutuhan masyarakat desa, setiap desa pada umumnya selalu melengkapi sarana dan fasilitas yang dapat mendukung kegiatan masyarakat desa. Beberapa sarana yang selalu ada di lingkungan desa adalah sarana penunjang yang dapat digunakan warga sehari-hari seperti sarana olahraga, sarana bermain, taman baca, dan lain-lain. Sarana penunjang seperti ini selayaknya dapat juga digunakan anak-anak untuk mengisi kegiatan sehari-hari terlebih selama masa pandemi saat ini, karena aktivitas di lingkungan sekolah juga dibatasi, sehingga membuat anak-anak nyaris tidak memiliki aktivitas yang berarti di bidang pembelejaran.

Namun masalah yang terjadi, pengelolaan sarana penunjang tersebut yang semakin tidak teratur, tidak menarik, terlebih disebabkan pembatasan sosial di masa pandemi menyebabkan sarana-sarana tersebut tidak dapat berfungsi sebagaimana biasa. Salah satu contoh adalah "Taman Baca Masyarakat" yang berada di Desa Kolam Kecamatan Percut Sei Tuan Kabupaten Deli Serdang yang tidak lagi berfungsi sebagaimana tujuan awal taman baca tersebut didirikan. Desa Kolam merupakan salah satu desa yang berada di Kecamatan Percut Sei Tuan, Kabupaten Deli Serdang, Sumatera Utara. Memiliki luas daerah sebesar $5,98 \mathrm{~km} 2$, dan berada pada $3^{0} 58^{\prime}$ Lintang Utara dan $98^{0} 73^{\prime}$ Bujur Timur. Desa Kolam terdiri atas 13 Dusun/Lingkungan, 3 RW dan 20 RT.
Termasuk dalam desa swadaya dengan jumlah penduduk sebanyak 17.418 jiwa, yang terbagi atas 8.832 laki-laki dan 8.586 perempuan dengan jumlah Kepala Keluarga sebanyak 4.012. Jumlah penduduk dengan kategori usia belum belum produktif (0-14 thn) sebanyak 5.539 jiwa, usia produktif (15 - 64 thn) sebanyak 11.252 jiwa, dan usia tidak produktif lagi $(65+)$ sebanyak 627 jiwa. Mayoritas penduduk Desa Kolam memiliki mata pencaharian di bidang pertanian, selebihnya di bidang perdagangan, industri rumah tangga, jasa, dan PNS/TNI/POLRI. Masyarakat Desa Kolam terdiri atas suku Jawa, Melayu, dan Batak, dengan mayoritas dipadati oleh suku Jawa.

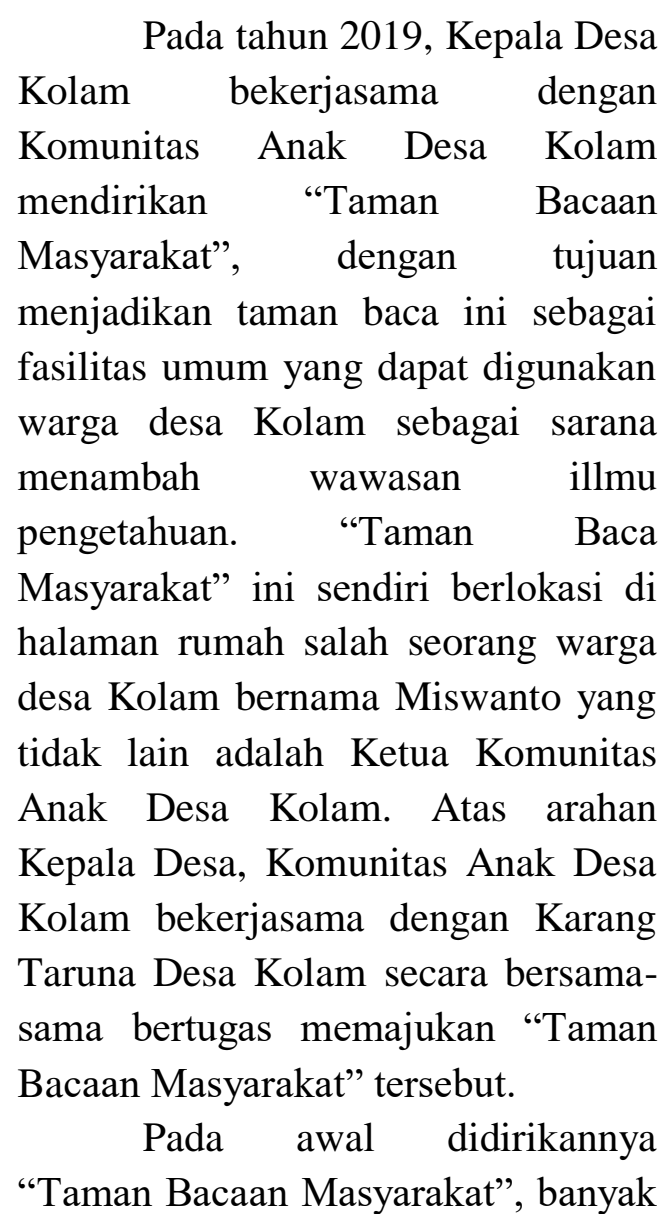


masyarakat terlebih anak-anak usia sekolah yang tertarik untuk berkunjung dan membaca buku-buku yang tersedia di taman baca tersebut. Namun setelah lebih kurang 3 tahun berjalan, taman

baca tersebut mengalami penurunan minat pengunjung disebabkan satu dan lain hal.

Berdasarkan wawancara yang dilakukan dengan Pak Miswanto (Ketua Komunitas Desa Anak Kolam) pada hari Senin 08 Maret 2021, penurunan minat pengunjung taman baca disebabkan oleh :

- Desain lokasi taman baca yang kurang ditata dengan baik agar terlihat lebih menarik dan dapat digunakan sebagai sarana belajar anak di masa pandemi Covid-19;

- Koleksi taman baca yang kurang variatif dan tidak diperbaharui;
- Pembatasan sosial yang diberlakukan selama masa pandemi Covid-19; dan

- Kurangnya pemahaman Komunitas Anak Desa Kolam dan Karang Taruna tentang pengelolaan taman baca yang menarik dan sesuai dengan standar protokol kesehatan di masa pandemic Covid-19.

Beberapa permasalahan di atas menjadi hal yang sangat urgen untuk disegera diselesaikan.

\section{METODE PENELITIAN}

Solusi yang ditawarkan untuk mengatasi permasalahan yang dihadapi Komunitas Anak Desa Kolam dan Karang Taruna Desa Kolam digambarkan pada tabel berikut :

Tabel 1. Solusi yang ditawarkan

\begin{tabular}{|c|c|c|c|c|}
\hline No & Permasalahan & Solusi & Luaran & Kuantitas \\
\hline 1 & $\begin{array}{l}\text { Pemahaman Mitra } \\
\text { terhadap tata kelola taman } \\
\text { baca sebagai sarana } \\
\text { pendukung belajar anak di } \\
\text { masa pandemi Covid-19 } \\
\text { masih kurang. }\end{array}$ & $\begin{array}{l}\text { Sosialisasi dan bimbingan } \\
\text { teknis penguatan tata } \\
\text { kelola "Taman Bacaan } \\
\text { Masyarakat" } \text { sebagai } \\
\text { sarana pendukung belajar } \\
\text { anak di masa pandemi } \\
\text { Covid-19 }\end{array}$ & $\begin{array}{l}\text { Buku pedoman tata } \\
\text { kelola taman baca } \\
\text { desa sebagai sarana } \\
\text { pendukung belajar } \\
\text { anak di masa pandemi } \\
\text { Covid-19. }\end{array}$ & $1 \mathrm{Buku}$ \\
\hline 2 & $\begin{array}{l}\text { Koleksi bahan bacaan di } \\
\text { "Taman } \\
\text { Masyarakat" } \\
\text { variatif. }\end{array}$ & $\begin{array}{l}\text { Pendampingan } \\
\text { pengembangan koleksi } \\
\text { bahan bacaan di "Taman } \\
\text { Bacaan Masyarakat yang } \\
\text { lebih variatif. }\end{array}$ & $\begin{array}{l}\text { Buku pengayaan, } \\
\text { buku cerita, buku } \\
\text { dongeng, poster, } \\
\text { permainan tradisional } \\
\text { dan media belajar di } \\
\text { taman baca. }\end{array}$ & 1 paket \\
\hline 3 & $\begin{array}{l}\text { Desain lokasi "Taman } \\
\text { Bacaan Masyarakat" tidak } \\
\text { ditata dengan baik dan } \\
\text { kurang menarik untuk } \\
\text { dikunjungi. }\end{array}$ & $\begin{array}{l}\text { Pendampingan dalam } \\
\text { menata lokasi "Taman } \\
\text { Bacaan Masyarakat" } \\
\text { sebagai sarana pendukung } \\
\text { belajar anak di masa } \\
\text { pandemi Covid-19. }\end{array}$ & $\begin{array}{lr}\text { Pojok } & \text { Literasi } \\
\text { "Taman } & \text { Baca } \\
\text { Masyarakat" } & \text { Desa } \\
\text { Kolam yang lebih } \\
\text { menarik sebagai } \\
\text { sarana belajar anak di } \\
\text { masa pandemi Covid- } \\
19 .\end{array}$ & 1 paket \\
\hline
\end{tabular}


Wildansyah Lubis, Waliyul Maulana Sir, Jubaidah Hsb, Lala Jelita Ananda : Tata ....

Berdasarkan solusi yang pengabdian ini adalah sebagai ditawarkan, maka luaran kegiatan ini berikut : adalah sebagai berikut:

- Buku pedoman tata kelola taman baca desa.

- Pojok Literasi "Taman Bacaan Masyarakat" Desa Kolam sebagai sarana pendukung belajar anak di Masa Pandemi Covid-19.

- Koleksi Buku pengayaan, buku cerita, buku dongeng, poster, permainan tradisional dan media belajar di taman baca.

Secara sederhana, proses perolehan luaran yang akan dicapai dari kegiatan
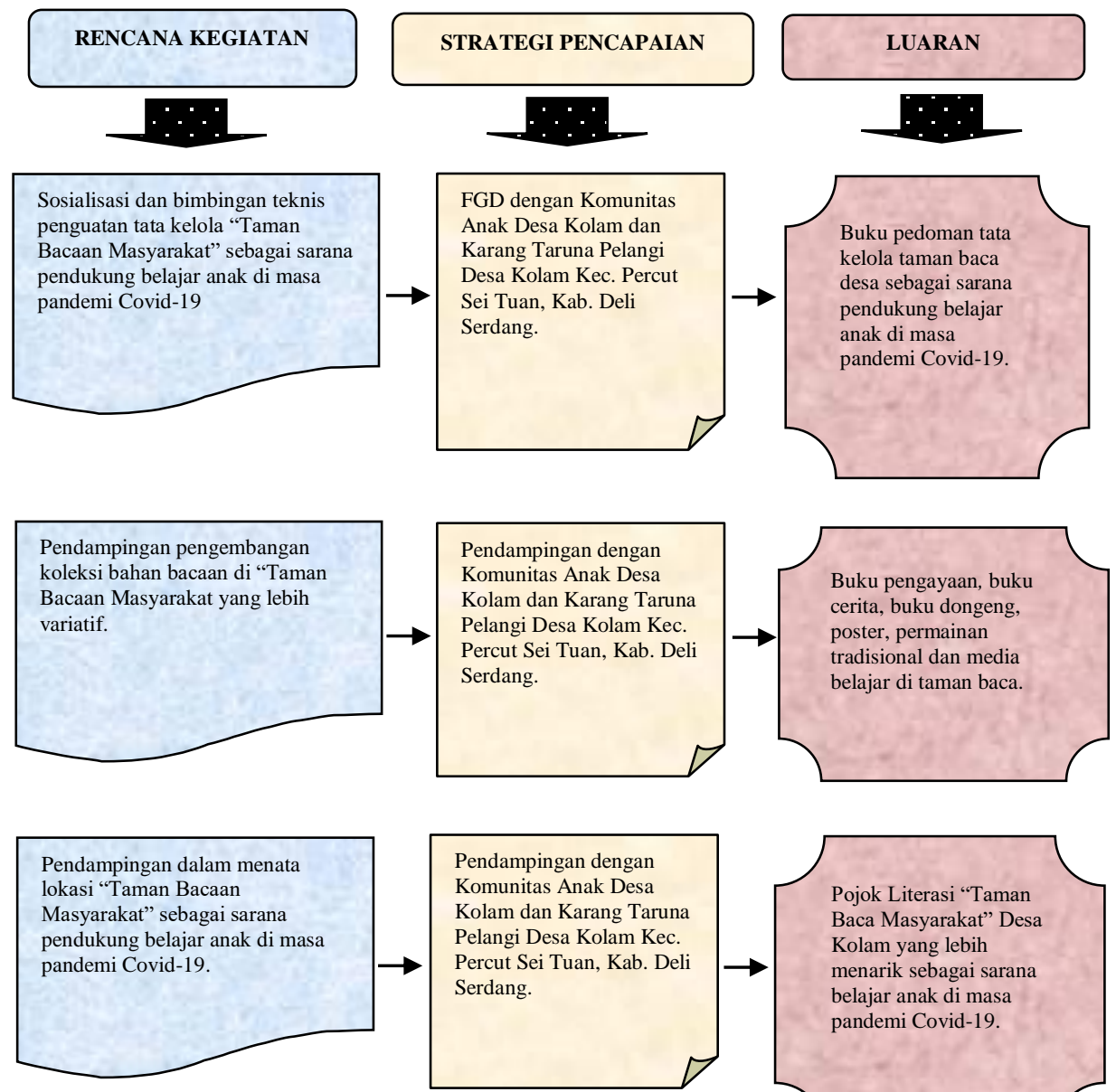

Pendampingan dengan Komunitas Anak Desa Kolam dan Karang Taruna Pelangi Desa Kolam Kec. Percut Sei Tuan, Kab. Deli Serdang.

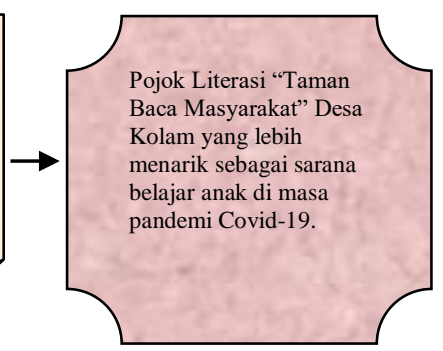


Berdasarkan gambar di atas, metode pelaksanaan kegiatan dapat dideskripsikan sebagai berikut :

1) Persiapan. Beberapa kegiatan yang dilakukan pada tahap persiapan antara lain :

a. Melakukan observasi awal untuk menjajaki profil mitra.

b. Menyepakati permasalahan prioritas mitra yang akan diselesaikan.

c. Menyepakati solusi yang akan dilaksanakan untuk menyelesaikan

permasalahan mitra.

2) Pelaksanaan. Beberapa kegiatan yang dilakukan pada tahap pelaksanaan adalah:

a. Melakukan sosialisasi dan bimbingan teknis penguatan tata kelola "Taman Bacaan

Masyarakat" Desa Kolam. Kegiatan ini bertujuan untuk memberikan penguatan pemahaman kepada mitra tentang tata kelola taman baca desa sebagai sarana pendukung belajar anak di masa pandemi Covid-19.

b. Melakukan pendampingan pengembangan koleksi buku "Taman Bacaan Masyarakat” Desa kolam. Kegiatan ini bertujuan untuk menambah variasi bahan bacaan yang tersedia "Taman Bacaan Masyarakat” Desa kolam. c. Melakukan pendampingan dalam menata lokasi "Taman Bacaan Masyarakat" Desa kolam. Kegiatan ini bertujuan untuk mendekorasi ulang taman baca agar terlihat lebih menarik dan dapat dijadikan sebagai sarana belajar anak di masa pandemi Covid-19.

3) Monitoring dan Evaluasi. Beberapa kegiatan yang dilakukan pada tahap monitoring dan evaluasi adalah :

a. Melakukan evaluasi proses yang bertujuan untuk mengukur ketercapaian program terutama pada aspek pemahaman mitra tentang tata kelola taman baca masyarakat di desa.

b. Melakukan evaluasi hasil yang bertujuan untuk mengukur ketercapaian program yang berdampak pada efektivitas pemanfaatan "Taman Bacaan Masyarakat" Desa Kolam sebagai sarana pendukung belajar anak di masa pandemi Covid-19.

4) Tindak Lanjut. Kegiatan yang dilakukan pada tahap tindak lanjut adalah :

a. Menjadikan Desa Kolam menjadi desa binaan LPPM UNIMED berkelanjutan

b. Melakukan program yang sama dengan lingkup yang lebih luas di Desa, 
Wildansyah Lubis, Waliyul Maulana Sir, Jubaidah Hsb, Lala Jelita Ananda : Tata ....

Kecamatan dan Kabupaten lain di Sumatera Utara.

\section{HASIL PENELITIAN DAN PEMBAHASAN}

Hasil yang dicapai dalam kegiatan Pengabdian Kepada Masyarakat ini adalah :

\section{A. Persiapan}

Beberapa kegiatan yang dilakukan pada tahap persiapan adalah:

\section{a. Melakukan observasi awal untuk menjajaki profil mitra.}

Kegiatan ini dilakukan pada tanggal 08 Maret 2021, tim Pengabdian Kepada Masyarakat (PKM) mengunjungi "Taman Baca Masyarakat Melati” di Jl. Sukmo Dusun XII Desa Kolam untuk melakukan penjajakan terhadap Mitra. Mitra dalam kegiatan PKM ini terdiri atas 2 yaitu : Komunitas Anak Desa Kolam dan Karang Taruna Pelangi Desa Kolam. Melalui pertemuan ini diperoleh data beberapa permasalahan yang dihadapi oleh mitra, yaitu :

1. Terdapat "Taman Bacaan Masyarakat" di Desa Kolam yang berpotensi sebagai sarana belajar anak di masa Pandemi Covid-19 namun tidak berfungsi dan tidak dikelola dengan baik.

2. Kurangnya Pemahaman mitrat tentang pengelolaan "Taman Bacaan Masyarakat" sebagai sarana belajar anak di masa Pandemi Covid-19.

3. Koleksi Koleksi di "Taman Bacaan Masyarakat” Desa Kolam yang kurang variatif.

4. Desain lokasi "Taman Bacaan Masyarakat" yang kurang menarik sehingga anak-anak tidak berminat untuk berkunjung
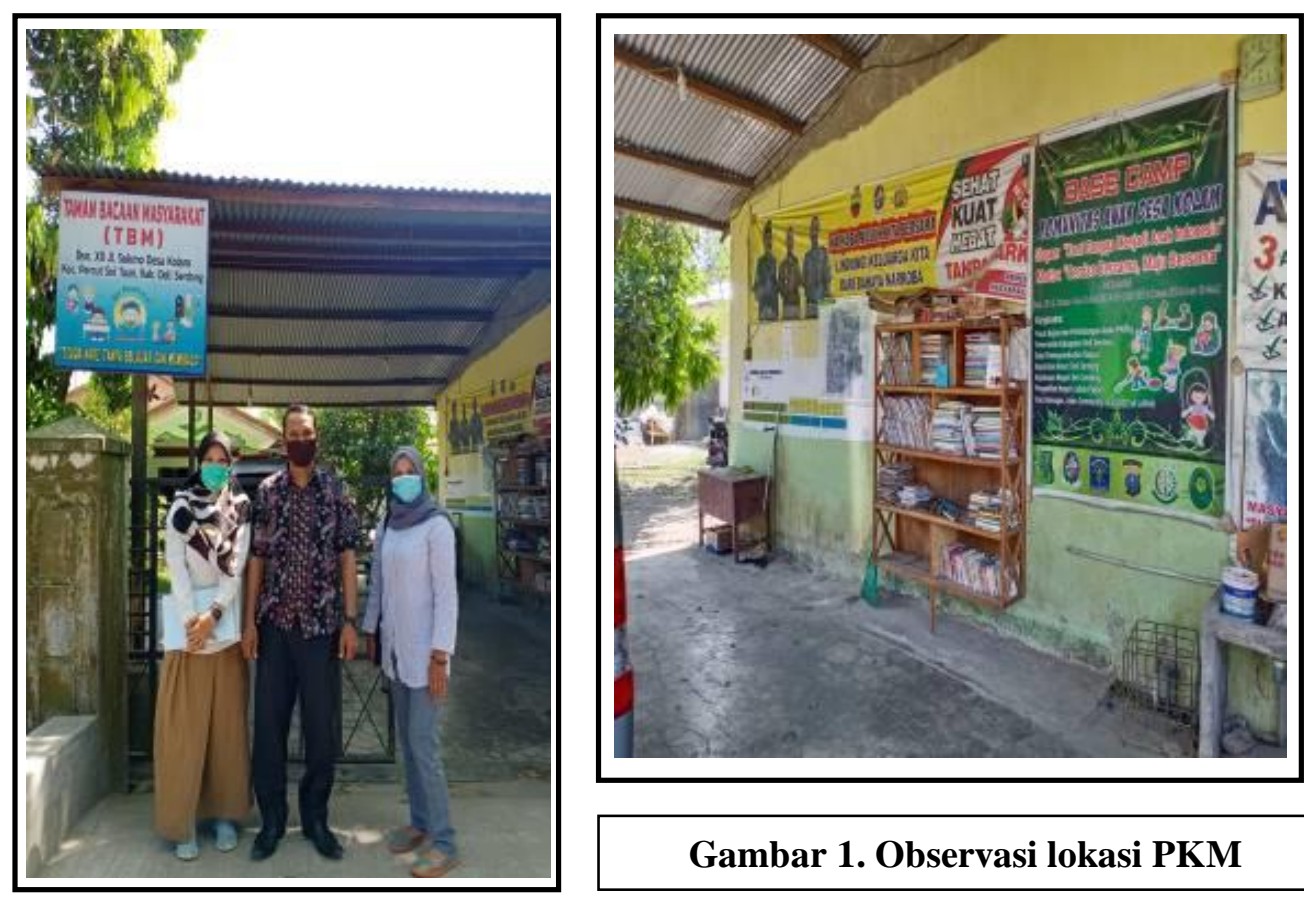

Gambar 1. Observasi lokasi PKM 


\section{b. Menyepakati permasalahan prioritas mitra yang akan diselesaikan.}

\author{
Berdasarkan hasil observasi \\ awal, disepakati permasalahan \\ prioritas mitra yang akan \\ diselesaikan, yaitu:
}

1. Kebutuhan Desa Kolam terhadap sarana pendukung belajar anak di masa pandemi Covid-19.

2. Lokasi taman baca yang kurang ditata dengan baik agar terlihat lebih menarik untuk dikunjungi.

3. Kurang variatifnya koleksi bahan bacaan yang tersedia di taman baca.
4. Kurangnya pemahaman Komunitas Anak Desa Kolam dan Karang Taruna Desa Kolam terhadap standar pengelolaan taman baca sebagai sarana belajar anak di masa pandemi Covid-19.

c. Menyepakati solusi yang akan dilaksanakan untuk menyelesaikan masalah mitra.

Dari beberapa permasalahan yang telah disepakati, lalu sepakatilah solusi permasalahan yang akan dilaksanakan, yaitu :

Tabel 2. Solusi yang disepakati

\begin{tabular}{|c|c|c|c|c|}
\hline No & Permasalahan & Solusi & Luaran & Kuantitas \\
\hline 1 & $\begin{array}{l}\text { Pemahaman Mitra } \\
\text { terhadap tata kelola taman } \\
\text { baca sebagai sarana } \\
\text { pendukung belajar anak di } \\
\text { masa pandemi Covid-19 } \\
\text { masih kurang. }\end{array}$ & $\begin{array}{l}\text { Sosialisasi dan } \\
\text { bimbingan teknis } \\
\text { penguatan tata kelola } \\
\text { "Taman Bacaan } \\
\text { Masyarakat" sebagai } \\
\text { sarana pendukung } \\
\text { belajar anak di masa } \\
\text { pandemi Covid-19 }\end{array}$ & $\begin{array}{l}\text { Buku pedoman tata } \\
\text { kelola taman baca } \\
\text { desa sebagai sarana } \\
\text { pendukung belajar } \\
\text { anak di masa pandemi } \\
\text { Covid-19. }\end{array}$ & 1 Buku \\
\hline 2 & $\begin{array}{l}\text { Koleksi bahan bacaan di } \\
\text { "Taman } \\
\text { Macaan } \\
\text { Masyarakat" } \\
\text { variatif. }\end{array}$ & $\begin{array}{l}\text { Pendampingan } \\
\text { pengembangan } \\
\text { koleksi bahan bacaan } \\
\text { di "Taman Bacaan } \\
\text { Masyarakat yang } \\
\text { lebih variatif. }\end{array}$ & $\begin{array}{l}\text { Buku pengayaan, } \\
\text { buku cerita, buku } \\
\text { dongeng, poster, } \\
\text { permainan tradisional } \\
\text { dan media belajar di } \\
\text { taman baca. }\end{array}$ & 1 paket \\
\hline 3 & $\begin{array}{l}\text { Desain lokasi "Taman } \\
\text { Bacaan Masyarakat" tidak } \\
\text { ditata dengan baik dan } \\
\text { kurang menarik untuk } \\
\text { dikunjungi. }\end{array}$ & $\begin{array}{l}\text { Pendampingan dalam } \\
\text { menata lokasi } \\
\text { "Taman Bacaan } \\
\text { Masyarakat" sebagai } \\
\text { sarana pendukung } \\
\text { belajar anak di masa } \\
\text { pandemi Covid-19. }\end{array}$ & $\begin{array}{lr}\text { Pojok } & \text { Literasi } \\
\text { "Taman } & \text { Baca } \\
\text { Masyarakat" } & \text { Desa } \\
\text { Kolam yang lebih } \\
\text { menarik sebagai } \\
\text { sarana belajar anak di } \\
\text { masa pandemi Covid- } \\
19 .\end{array}$ & 1 paket \\
\hline
\end{tabular}

\section{B. Pelaksanaan}

Kegiatan yang dilakukan pada tahap pelaksanaan yaitu:

a. Melakukan sosialisasi dan bimbingan teknis penguatan tata

\section{kelola "Taman Bacaan Masyarakat" Desa Kolam.}

Kegiatan ini dilakukan pada hari Senin, 26 Juli 2021 di "Taman Bacaan Masyarakat Melati” Jl. Sukmo Dusun XII Desa Kolam. 
Wildansyah Lubis, Waliyul Maulana Sir, Jubaidah Hsb, Lala Jelita Ananda : Tata ....

Kegiatan ini bertujuan untuk memberikan penguatan pemahaman kepada mitra yaitu Komunitas Anak Desa Kolam dan Karang Taruna Pelangi Desa Kolam tentang tata kelola taman baca desa sebagai sarana pendukung belajar anak di masa pandemi Covid-19.

Kegiatan ini dihadiri oleh Tim Pengabdian Kepada Masyarakat, Mahasiswa, Kepala Desa Kolam (Bpk. Jufri Purwanto), Pembina Karang Taruna Desa Kolam (Bpk.
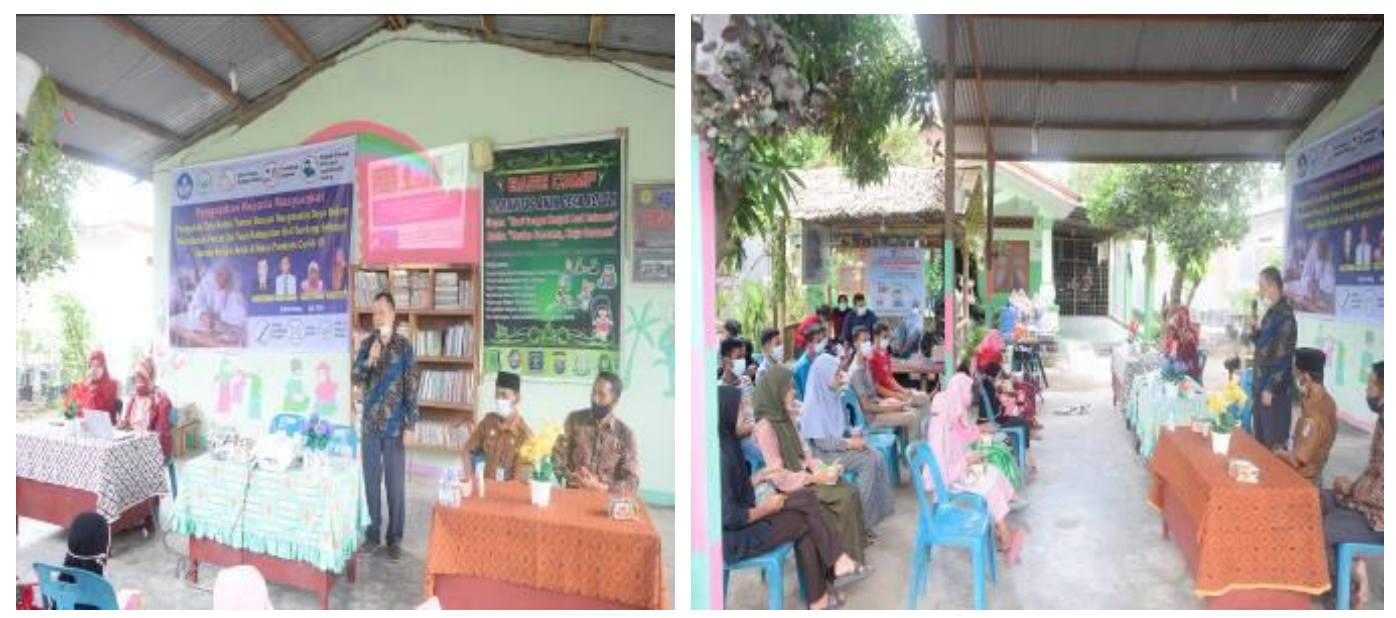

Gambar 2. Pelaksanaan Kegiatan Sosialisasi dan Bimbingan Teknis Penguatan Tata Kelola "Taman Bacaan Masyarakat" Desa Kolam sebagai Sarana Belajar Anak di Masa Pandemic Covid-19

Pada kegiatan ini, mitra diberikan bimbingan dan penguatan tentang tata kelola taman bacaan masyarakat di masa Covid-19 melalui pemaparan materi oleh Narasumber Jubaidah, S.Pd., M.Pd (Ahli Pendidikan Masyarakat). Materi yang diberikan berisi tentang teknis
Miswanto), dan sejumlah 35 orang peserta dari Mitra PKM (Komunitas Anak Desa Kolam dan Karang Taruna Desa Kolam). 


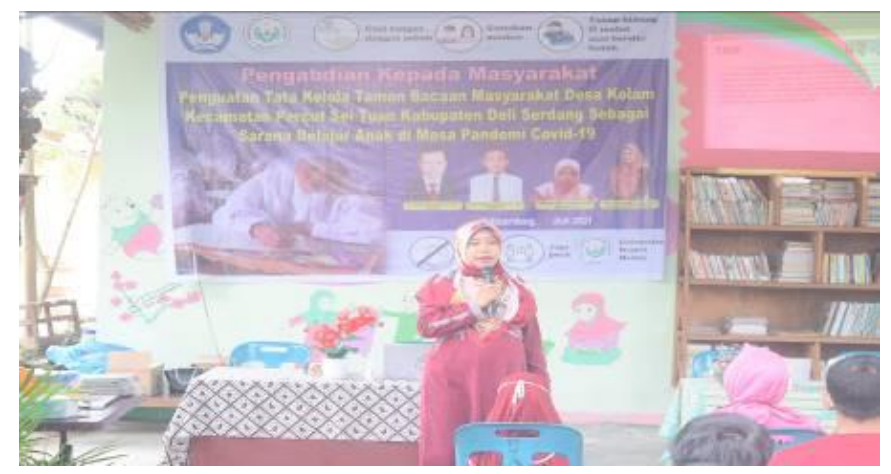

Gambar 3. Narasumber menyampaikan materi Tata Kelola Taman Bacaan Masyarakat sebagai Sarana Belajar Anak di Masa Pandemic Covid-19

b. Melakukan pendampingan dalam menata lokasi dan pengembangan koleksi buku "Taman Bacaan Masyarakat" Desa kolam.

Kegiatan ini bertujuan untuk menambah variasi bahan bacaan yang tersedia "Taman Bacaan Masyarakat" Desa kolam. Melalui dana PNBP Unimed 2021, tim PKM menyediakan Pojok Literasi beserta Koleksi
Bahan Bacaan bagi anak serta Permainan Tradisional untuk Taman Bacaan Masyarakat Melati di Desa Kolam ini. Pojok literasi juga dilengkapi galon air sebagai sarana pengunjung untuk tetap menjaga kebersihan tangan, juga Standing Banner yang berisi informasi sebagai aturan yang harus dipatuhi oleh pengunjung pada saat berkunjung ke taman baca, mengingat saat ini masih dalam kondisi Pandemic Covid-19.

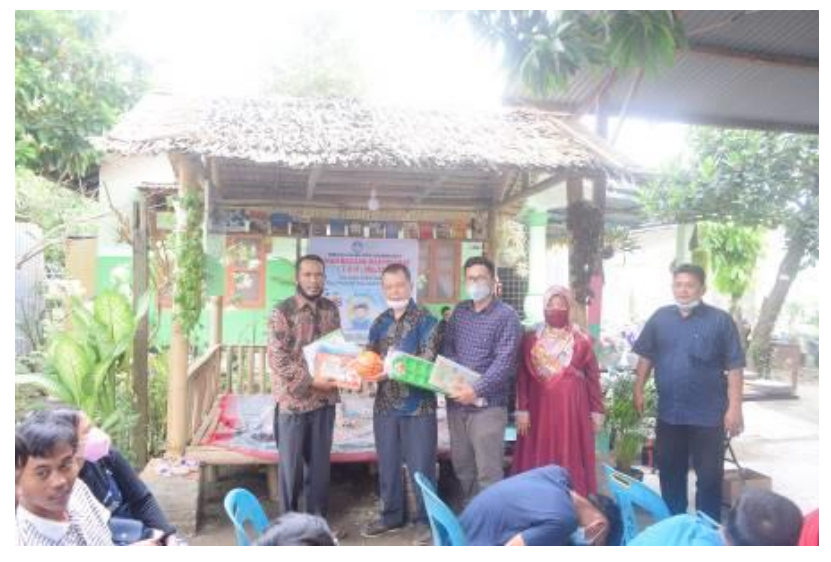

Gambar 4. Penyerahan secara resmi Pojok Literasi, Bahan Bacaan dan Permainan Tradisional dari Tim PKM, Perwakilan dari LPPM UNIMED kepada Kepala Desa Kolam

\section{SIMPULAN}

Kegiatan penguatan tata kelola “Taman Bacaan Masyarakat" sebagai sarana pendukung belajar anak di masa pandemi Covid-19 telah membawa dampak yang positif 
Wildansyah Lubis, Waliyul Maulana Sir, Jubaidah Hsb, Lala Jelita Ananda : Tata ....

terhadap kebermanfaatan Taman Bacaan Masyarakat Desa Kolam.

Hasil Kegiatan Sosialisasi dan Bimbingan Teknis yang dilakukan telah menghasilkan luaran: 1) Koleksi Buku pengayaan, buku cerita, buku dongeng, Permainan tradisional dan media belajar di taman bacaan masyarakat; 2) Pojok Literasi; 3) Video Pelaksanaan Kegiatan

\section{DAFTAR RUJUKAN}

Badan Pusat Statistik Kabupaten Deli Serdang. 2021. Kabupaten Deli Serdang Dalam Angka 2021. Deli Serdang: Badan Pusat Statistik.

Badan Pusat Statistik Kabupaten Deli Serdang. 2020. Kecamatan Percut Sei Tuan Dalam Angka 2020. Deli Serdang: Badan Pusat Statistik.

Darmono. 2016. Standar Pengelolaan Perpustakaan Desa/Kelurahan Sesuai dengan SNP 005:2011. Makalah. Disampaikan pada pelatihan Pengelolaan Perpustakaan Kelurahan di Kota Malang tgl 23-24 Februari 2016.

Jane, Octroaica Cempaka. 2013. Peran Taman Bacaan Masyarakat dalam Menumbuhkan Budaya Baca Anak di Taman Bacaan Masyarakat "Mortir" Banyumanik-Semarang. Jurnal Ilmu Perpustakaan. Vol 2, No 2 Thn 2013. Universitas Diponegoro.

Lembaga Penelitian dan Pengabdian kepada Masyarakat Unimed.
2021. Panduan Pelaksanaan Penelitian dan Pengabdian Kepada Masyarakat. Medan: LPPM Unimed. 